\title{
Extracorporeal Shockwave Therapy Versus Kinesiology Taping in the Management of Plantar Fasciitis: A Randomized Clinical Trial
}

\author{
Banu ORDAHAN, Gözde TÜRKOĞLU, Ali Yavuz KARAHAN, Halil Ekrem AKKURT
}

Department of Physical Medicine and Rehabilitation, Konya Training and Research Hospital, Konya, Turkey

\begin{abstract}
Objectives: This study aims to compare the efficacy of extracorporeal shockwave therapy (ESWT) and kinesiology taping in the treatment of plantar fasciitis.

Patients and methods: The study included 80 patients diagnosed with plantar fasciitis. The patients were randomized into two groups as ESWT ( 9 males, 28 females; mean age $47.8 \pm 12.4$ years; range 40 to 55 years) and kinesiology taping (KT, 7 males, 26 females; mean age $47.7 \pm 9.8$ years; range 40 to 55 years) groups. Groups were similar regarding age, sex, and body mass index (all p>0.05). Three patients in ESWT group and seven patients in KT group were lost to follow-up. ESWT was applied once a week for five weeks, while KT was applied every five days for five weeks. Patients' pain and functional status were evaluated with visual analog scale, heel tenderness index, and foot and ankle outcome score before and after treatment. Results: At the study onset, there were no statistically significant differences between the two groups in their visual analog scale, heel tenderness index, and foot and ankle outcome scores. Five weeks later, both groups showed significant improvement in all parameters ( $\mathrm{p}<0.05$ ), but no significant differences were observed between the groups in the visual analog scale, heel tenderness index, and foot and ankle outcome score scores.

Conclusion: Both ESWT and KT treatments improved pain levels and function and quality of life in individuals with plantar fasciitis. Neither method was superior in treating plantar fasciitis.

Keywords: Extracorporeal shockwave therapy; kinesiology taping; pain; plantar fasciitis.
\end{abstract}

Plantar fasciitis (PF) is the most common cause of heel pain in adults. Although the exact cause is unknown, risk factors include middle age, obesity, excessive foot pronation, pes cavus, excessive running, pes planus, and prolonged standing. ${ }^{1,2}$ The underlying condition for $\mathrm{PF}$ is tissue breakdown near the site of origin of the plantar fascia at the medial tuberosity of the calcaneus. ${ }^{1,2}$ Patients may present with heel pain with their first steps in the morning or after prolonged sitting, and sharp pain with palpation of the medial plantar calcaneal region. ${ }^{3,4}$ Stretching the plantar fascia and weight-bearing on the heel activate symptoms. ${ }^{4}$

Conservative therapy provides significant relief in approximately $90 \%$ of patients with PF. ${ }^{1}$ Numerous methods are in use to treat PF, including nonsteroidal anti-inflammatory drugs, cortisone injections, foot orthoses, physical therapy, stretching exercises, night splints, and extracorporeal shockwave therapy (ESWT). ${ }^{5-8}$ A small number of patients undergo surgery, including spur resection and release of all parts of the fascial band. ${ }^{8}$ ESWT is a relatively new treatment used to alleviate heel pain, as well as other conditions, including tennis elbow, calcifying tendinopathy of the shoulder, and non-union fractures of the long bones. ${ }^{9}$

Another method for treating PF is kinesiology taping (KT), which is widely indicated in musculoskeletal pathologies. It facilitates circulation and motion, elevates skin and subcutaneous interstitial tissues, decreases inflammation and pain, increases performance, enhances 
neuromuscular re-education, prevents injury, and speeds recovery. ${ }^{10}$ Different applications and indications are currently under investigation, and data are accumulating. Supportive taping is an effective short-term treatment for plantar heel pain. ${ }^{11}$ Low-Dye taping is one of the most widely used techniques for treating PF. ${ }^{12}$ To the best of our knowledge, no studies have compared ESWT and $\mathrm{KT}$ in the treatment of PF to date. Therefore, in this study, we aimed to compare the efficacy of ESWT and KT in the treatment of PF.

\section{PATIENTS AND METHODS}

We conducted this randomized clinical trial with a follow-up for five weeks at Konya Training and Research Hospital Outpatient Clinic of Physical Medicine and Rehabilitation Department between November 2015 and February 2016. A total of 99 consecutive patients with plantar heel pain were screened for admission into the trial. Of them, 19 consecutive bilateral PF patients were not considered. Thus, 80 patients satisfied the eligibility criteria and were randomized into two groups as ESWT and KT groups (Figure 1). In the ESWT group, three patients did not appear for their assigned treatment regularly; therefore, the group included nine males and 28 females (mean age $47.8 \pm 12.4$ years; range 40 to 55 years). In the KT group, five patients did not appear for their assigned treatment regularly, and two patients received steroid injections due to severe pain; therefore, the group included seven males and 26 females (mean age $47.7 \pm 9.8$ years; range 40 to 55 years). The diagnosis of $\mathrm{PF}$ was based on tenderness localized to the medial tubercle of the calcaneus, and pain that started with the first step in the morning and worsened with weight-bearing activity. Assessments were performed before the procedure and at five-week follow-up visit. The following inclusion criteria were used: pain (i) was reported with palpation of the plantar fascia, (ii) was localized and sharp but not radiating, (iii) was worse with the initial step after an extended period of rest, and (iv) decreased initially after the first few steps but exacerbated with increased activity. ${ }^{13}$ Exclusion criteria comprised (i) history of previous steroid injections, (ii) previous foot surgery, lumbar spine disc herniation or back injury, or (iii) history of rheumatic disease. The study protocol was approved by the Medical Faculty of Selçuk University Ethics Committee. A written informed consent was obtained from each patient. The study was conducted in accordance with the principles of the Declaration of Helsinki.

The ESWT (Dornier Compact Delta: Germany) was performed once a week for five weeks, on the $12-15 \mathrm{~Hz}$ frequency setting; 2500 pulses at two-three bar pressure were applied. During ESWT sessions, patients were in a prone position with

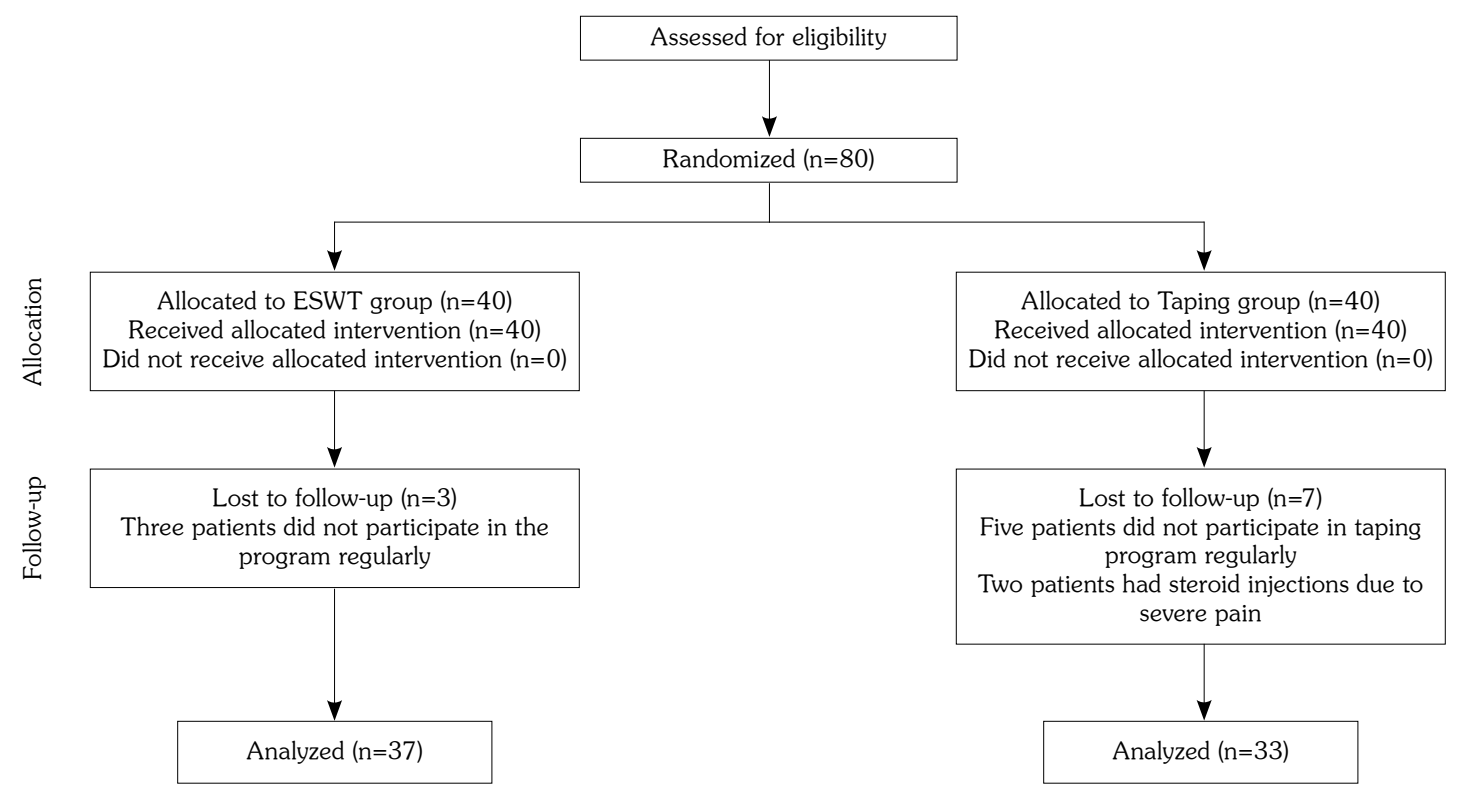

Figure 1. Flow diagram of patients recruited for this study. ESWT: Extracorporeal shockwave therapy. 


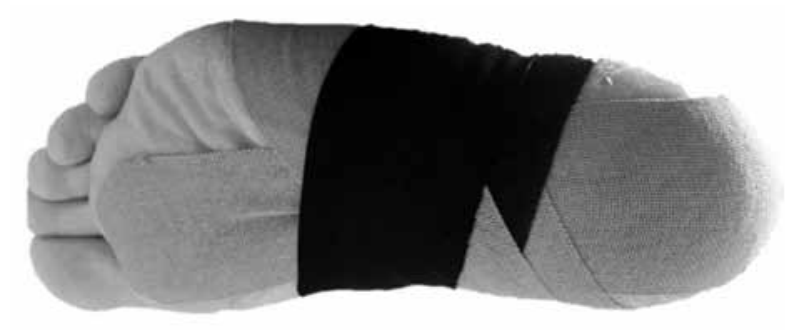

Figure 2. Kinesiology taping protocol.

their feet extending beyond the examination table, and their knee and hip joints in a neutral position. Using ultrasound gel as a coupling medium, the head of ESWT shock wave device was applied to the inferior aspect of the calcaneus. The target area was the region of maximum tenderness in the medial calcaneus. No local anesthetic was applied. All patients were allowed for weight-bearing.

As part of the KT protocol, the target $\mathrm{KT}$ site was marked, starting from the posterior margin of the calcaneus bone and ending at the metatarsal joints. During the procedure, patients were in a prone position with their knee joints and ankle joints in a neutral position. Kinesiology tape was first applied from the calcaneus to the metatarsal heads with maximum stretching toward the plantar fascia. Four horizontal pieces were applied to the soles of the feet to support the medial arch. The first horizontal piece was applied from the lateral malleolus to the medial aspect of the foot, and then the second piece was applied from the medial malleolus to the lateral aspect of the foot. The third and fourth pieces followed the same pattern with an overlap of approximately one-third of the width of the tape. The horizontal pieces were applied with maximum stretching (Figure 2). The KT procedure was repeated every five days for five weeks. ${ }^{10}$ The tape (Kinesio Tex, Kinesio Taping, US) used for this study was waterproof, porous, and adhesive.

Pain levels were assessed using a $100 \mathrm{~mm}$ horizontal visual analog scale (VAS) and physician assessment of heel pain on palpation using the heel tenderness index (HTI: $0=$ no pain, $1=$ painful, $2=$ painful and winces and $3=$ painful, winces and withdraws). Pain levels were assessed before and after the treatment.

Function and quality of life were measured using the foot and ankle outcome score (FAOS). ${ }^{14}$
The FAOS is a 42-item questionnaire divided into five subscales: pain, other symptoms, activities of daily living, sports, and recreation function and foot and ankle-related quality of life. The pain subscale contains nine items, the other symptoms subscale contains seven items, the activities of daily living subscale contains 17 items, the sports and recreation function subscale contains five items, and the foot, and ankle-related quality of life subscale contains four items. Each question is scored on a 5-point Likert scale (from 0 to 4), and each of the five subscale scores is calculated by adding the included subscale items. The raw scores are then transformed into a final score of 0 to 100 (from worst to best outcomes). The reliability of the Turkish FAOS was previously verified. ${ }^{14}$

Concealed allocation of subjects was performed by using a computer-generated randomized table of numbers created before the beginning of the study. All outcome measures were collected by the same researcher, who was blinded to the patient group assignment at the beginning of the study and at the five-week follow-up.

\section{Statistical analysis}

The SPSS for Windows 15.0 software package (SPSS Inc., Chicago, IL, USA) was used for the statistical evaluation of the data. Conformity of continuous variables with normal distribution was investigated using the Kolmogorov-Smirnov test. All variables were distributed normally. Descriptive data were presented as the mean \pm standard deviation. Demographic and clinical characteristics were compared using the Chi-square test. Within-group and between-group differences were investigated. The independent samples t-test was used to compare the two groups. The paired-samples t-test was used to analyze the differences between the baseline and after treatment values. A $p$ value less than 0.05 was considered statistically significant.

\section{RESULTS}

The ESWT and KT groups were similar regarding age, sex, and body mass index (all p>0.05) (Table 1). At the study onset, there were no statistically significant differences between the two groups in their VAS and HTI scores, and FAOS. 
Table 1. Demographic and clinical characteristics of patients

\begin{tabular}{|c|c|c|c|c|c|}
\hline & \multicolumn{2}{|c|}{ ESWT $(n=37)$} & \multicolumn{2}{|c|}{$\mathrm{KT}(\mathrm{n}=33)$} & \multirow[b]{2}{*}{$p$} \\
\hline & $\mathrm{n}$ & Mean \pm SD & $\mathrm{n}$ & Mean \pm SD & \\
\hline Age (year) & & $47.8 \pm 12.4$ & & $47.7 \pm 9.8$ & 0.642 \\
\hline Sex & & & & & 0.965 \\
\hline Female & 28 & & 26 & & \\
\hline Male & 9 & & 7 & & \\
\hline Body mass index $\left(\mathrm{kg} / \mathrm{m}^{2}\right)$ & & $32.2 \pm 4.9$ & & $31.9 \pm 7.2$ & 0.343 \\
\hline
\end{tabular}

Five weeks later, both groups showed significant improvement in all parameters within the groups (all $\mathrm{p}<0.05$ ), but no significant differences were observed between the groups in the VAS and HTI scores (Table 1) and FAOS (Table 2).

\section{DISCUSSION}

In this randomized study, we compared ESWT to $\mathrm{KT}$ in patients with PF. To our knowledge, this is the first study to compare ESWT with KT. We observed significant improvement in the VAS and HTI scores, and FAOS in both groups. Possible benefits of KT include increased interstitial space, promoting better blood and lymph flow in the region, decreased inflammation and pain, and quicker recovery. ${ }^{10}$ The efficacy of arch support taping in patients with PF has been shown in previous studies. ${ }^{11-13,15-19}$ Several techniques are utilized in clinical practice. The most common techniques are low-Dye taping and augmented low-Dye taping. ${ }^{12,15,18}$ Taping applications that decrease pronation are short-term interventions that have been shown to reduce pain in participants with PF. ${ }^{13,16}$ Low-Dye taping and augmented low-Dye taping decrease pronation and increase dynamic medial longitudinal arch height during walking and jogging. ${ }^{15,18,19}$ Additionally, KT has been found to decrease pressure under the medial and lateral rearfoot while walking. ${ }^{15,17}$ Low-Dye taping supports the longitudinal arch of the foot. It has been shown to significantly reduce peak plantar pressures of normal feet during gait, especially the peak plantar pressure in the medial midfoot, and thus could reasonably be expected to help in the management of PF. ${ }^{20,21}$ A recent clinical practice guideline ${ }^{8}$ recommends that over-the-counter arch support should be considered as part of initial treatment options. Low-Dye taping supports the longitudinal arch of the foot, so low-Dye taping may be a viable alternative to foot orthoses for individuals who cannot tolerate the plantar pressures of an orthotic or for footwear that will not accommodate conventional insoles.

Like KT, ESWT is widely used in the treatment of PF. The efficacy and safety of ESWT on chronic $P F$ have been demonstrated in several randomized clinical trials. ${ }^{22-26}$ ESWT causes extreme excitement of the axon, destroys unmyelinated sensory fibers, improves symptoms by initiating an inflammatory

\begin{tabular}{|c|c|c|c|}
\hline & ESWT $(n=37)$ & KT $(n=33)$ & ESWT vs.KT \\
\hline & Mean \pm SD & $\overline{\text { Mean } \pm S D}$ & $p$ \\
\hline \multicolumn{4}{|l|}{ Visual analog scale } \\
\hline Baseline & $6.9 \pm 1.7$ & $7.4 \pm 2.0$ & 0.670 \\
\hline After treatment & $3.8 \pm 1.8$ & $3.6 \pm 2.3$ & 0.584 \\
\hline$p$ & $0.037 \dagger$ & $0.036 \dagger$ & \\
\hline \multicolumn{4}{|c|}{ Heel tenderness index } \\
\hline Baseline & $1.9 \pm 1.0$ & $2.1 \pm 1.2$ & 0.731 \\
\hline After treatment & $0.6 \pm 0.5$ & $0.8 \pm 0.5$ & 0.673 \\
\hline$p$ & $0.024 \dagger$ & $0.028 \dagger$ & \\
\hline
\end{tabular}




\begin{tabular}{|c|c|c|c|}
\hline & ESWT $(n=37)$ & $\mathrm{KT}(\mathrm{n}=33)$ & ESWT vs. KT \\
\hline & Mean \pm SD & Mean \pm SD & $p$ \\
\hline \multicolumn{4}{|l|}{ FAOS pain } \\
\hline Baseline & $45.7 \pm 17.2$ & $41.8 \pm 17.5$ & 0.721 \\
\hline After treatment & $55.8 \pm 11.2$ & $56.9 \pm 10.9$ & 0.643 \\
\hline$p$ & $0.019 \dagger$ & $0.018 \dagger$ & \\
\hline \multicolumn{4}{|l|}{ FAOS symptoms } \\
\hline Baseline & $57.5 \pm 24.9$ & $57.0 \pm 24.0$ & 0.921 \\
\hline After treatment & $68.3 \pm 25.0$ & $66.9 \pm 22.3$ & 0.345 \\
\hline$p$ & $0.024 \dagger$ & $0.027 \dagger$ & \\
\hline \multicolumn{4}{|l|}{ FAOS ADL } \\
\hline Baseline & $43.6 \pm 19.1$ & $46.6 \pm 17.6$ & 0.611 \\
\hline After treatment & $57.8 \pm 21.5$ & $59.8 \pm 20.3$ & 0.673 \\
\hline$p$ & $0.020 \dagger$ & $0.018 \dagger$ & \\
\hline \multicolumn{4}{|l|}{ FAOS SPORT } \\
\hline Baseline & $41.4 \pm 21.2$ & $42.8 \pm 19.5$ & 0.651 \\
\hline After treatment & $55.9 \pm 26.9$ & $57.2 \pm 24.2$ & 0.724 \\
\hline$p$ & $0.021 \dagger$ & $0.021 \dagger$ & \\
\hline \multicolumn{4}{|l|}{ FAOS QOL } \\
\hline Baseline & $44.5 \pm 9.4$ & $46.8 \pm 1$ & 0.856 \\
\hline After treatment & $58.6 \pm 14.6$ & $62.8 \pm 2$ & 0.584 \\
\hline$p$ & $0.019 \dagger$ & $0.020 \dagger$ & \\
\hline
\end{tabular}

response to the secretion of growth factors or nitrous oxide and revitalizes tissues by increasing angiogenesis. ${ }^{3,9}$ Some researchers have reported that ESWT is effective in the treatment of PF in comparison to a control group. ${ }^{25,26}$ However, other relevant studies have found no benefit to ESWT for PF. ${ }^{27,28}$ This discrepancy may be explained by methodological differences. For example, the use of local anesthesia, ${ }^{23,29,30}$ applicator position, ${ }^{23}$ and the use of different energy densities of ESWT ${ }^{31}$ are all factors that may have affected study results. In a study by Lee et al., ${ }^{31}$ a medium-energy $\left(0.16 \mathrm{mj} / \mathrm{mm}^{2}\right)$ ESWT group showed statistically significant pain reduction and improved function scores compared to a low-energy $\left(0.08 \mathrm{mj} / \mathrm{mm}^{2}\right)$ group. In another study, Park et al. ${ }^{32}$ measured the long-term effects of ESWT on PF and found that subjective pain began to decrease one week after the first treatment session, and continued to improve with time, up to a mean of 24 months. KT and ESWT have several advantages over surgery in the treatment of PF. Both ESWT and taping do not require patients to avoid weightbearing, and allow patients to return to work and the activities of daily life within just one or two days.

Both ESWT and KT have been shown in previous studies to be effective in treating
PF. 13,15-21,25,26 In our study, neither method was found to be superior in treating PF.

The major limitation of our study is the lack of a control group, while other limitations include a short follow-up duration, and absence of objective evaluations of the plantar fascia, such as ultrasonography. Nevertheless, a five-week follow-up period is common in many studies for evaluating pain, and the effect of pain on daily activities, in the management of PF. ${ }^{6}$ Ultrasonography is an effective diagnostic imaging tool for $\mathrm{PF}, 6,32$ and the absence of ultrasonographic measures of the thickness of the plantar fascia is another limitation of this study.

In conclusion, both ESWT and KT treatments improved pain levels and function and quality of life in individuals with PF. Neither method is superior in treating PF. In the future, well-designed case-control studies evaluating the long-term effects of these treatments should be conducted.

\section{Declaration of conflicting interests}

The authors declared no conflicts of interest with respect to the authorship and/or publication of this article. 


\section{Funding}

The authors received no financial support for the research and/or authorship of this article.

\section{REFERENCES}

1. Goff JD, Crawford R. Diagnosis and treatment of plantar fasciitis. Am Fam Physician 2011;84:676-82.

2. Roxas M. Plantar fasciitis: diagnosis and therapeutic considerations. Altern Med Rev 2005;10:83-93.

3. Chang KV, Chen SY, Chen WS, Tu YK, Chien KL. Comparative effectiveness of focused shock wave therapy of different intensity levels and radial shock wave therapy for treating plantar fasciitis: a systematic review and network meta-analysis. Arch Phys Med Rehabil 2012;93:1259-68.

4. Tu P, Bytomski JR. Diagnosis of heel pain. Am Fam Physician 2011;84:909-16.

5. League AC. Current concepts review: plantar fasciitis. Foot Ankle Int 2008;29:358-66.

6. Yucel U, Kucuksen S, Cingoz HT, Anliacik E, Ozbek $\mathrm{O}$, Salli $\mathrm{A}$, et al. Full-length silicone insoles versus ultrasound-guided corticosteroid injection in the management of plantar fasciitis: a randomized clinical trial. Prosthet Orthot Int 2013;37:471-6.

7. Wolgin M, Cook C, Graham C, Mauldin D. Conservative treatment of plantar heel pain: longterm follow-up. Foot Ankle Int 1994;15:97-102.

8. Thomas JL, Christensen JC, Kravitz SR, Mendicino RW, Schuberth JM, Vanore JV, et al. The diagnosis and treatment of heel pain: a clinical practice guidelinerevision 2010. J Foot Ankle Surg 2010;49:1-19.

9. Romeo P, Lavanga V, Pagani $\mathrm{D}$, Sansone V. Extracorporeal shock wave therapy in musculoskeletal disorders: a review. Med Princ Pract 2014;23:7-13.

10. Kase K, Wallis J, Kase T. Clinical Therapeutic Applications of the Kinesio Taping Methods Tokyo, Kinesio Taping Association, 2003.

11. Martin JE, Hosch JC, Goforth WP, Murff RT, Lynch DM, Odom RD. Mechanical treatment of plantar fasciitis. A prospective study. J Am Podiatr Med Assoc 2001;91:55-62.

12. Dye RW. A strapping. 1939. J Am Podiatr Med Assoc 2007;97:282-4.

13. Landorf KB, Radford JA, Keenan AM, Redmond AC. Effectiveness of low-Dye taping for the short-term management of plantar fasciitis. J Am Podiatr Med Assoc 2005;95:525-30.

14. Karatepe AG, Günaydin R, Kaya T, Karlibaş U, Özbek G. Validation of the Turkish version of the foot and ankle outcome score. Rheumatol Int 2009;30:169-73.

15. Van Lunen B, Cortes N, Andrus T, Walker M, Pasquale M, Onate J. Immediate effects of a heel-pain orthosis and an augmented low-dye taping on plantar pressures and pain in subjects with plantar fasciitis. Clin J Sport Med 2011;21:474-9.
16. Radford JA, Landorf KB, Buchbinder R, Cook C. Effectiveness of low-Dye taping for the short-term treatment of plantar heel pain: a randomised trial. BMC Musculoskelet Disord 2006;7:64.

17. Vicenzino B, McPoil T, Buckland S. Plantar foot pressures after the augmented low dye taping technique. J Athl Train 2007;42:374-80.

18. Franettovich M, Chapman A, Blanch P, Vicenzino B. A physiological and psychological basis for antipronation taping from a critical review of the literature. Sports Med 2008;38:617-31.

19. Cornwall MW, McPoil TG, Fair A. The effect of exercise and time on the height and width of the medial longitudinal arch following the modified reverse- 6 and the modified augmented low-dye taping procedures. Int J Sports Phys Ther 2014;9:635-43.

20. Scranton PE Jr, Pedegana LR, Whitesel JP. Gait analysis. Alterations in support phase forces using supportive devices. Am J Sports Med 1982;10:6-11.

21. Russo SJ, Chipchase LS. The effect of low-Dye taping on peak plantar pressures of normal feet during gait. Aust J Physiother 2001;47:239-44.

22. Schmitz C, Császár NB, Rompe JD, Chaves H, Furia JP. Treatment of chronic plantar fasciopathy with extracorporeal shock waves (review). J Orthop Surg Res 2013;8:31.

23. Rompe JD, Meurer A, Nafe B, Hofmann A, Gerdesmeyer L. Repetitive low-energy shock wave application without local anesthesia is more efficient than repetitive low-energy shock wave application with local anesthesia in the treatment of chronic plantar fasciitis. J Orthop Res 2005;23:931-41.

24. Dizon JN, Gonzalez-Suarez C, Zamora MT, Gambito ED. Effectiveness of extracorporeal shock wave therapy in chronic plantar fasciitis: a meta-analysis. Am J Phys Med Rehabil 2013;92:606-20.

25. Kudo P, Dainty K, Clarfield M, Coughlin L, Lavoie P, Lebrun C. Randomized, placebo-controlled, doubleblind clinical trial evaluating the treatment of plantar fasciitis with an extracoporeal shockwave therapy (ESWT) device: a North American confirmatory study. J Orthop Res 2006;24:115-23.

26. Malay DS, Pressman MM, Assili A, Kline JT, York $\mathrm{S}$, Buren B, et al. Extracorporeal shockwave therapy versus placebo for the treatment of chronic proximal plantar fasciitis: results of a randomized, placebocontrolled, double-blinded, multicenter intervention trial. J Foot Ankle Surg 2006;45:196-210.

27. Buchbinder R, Ptasznik R, Gordon J, Buchanan $\mathrm{J}$, Prabaharan V, Forbes A. Ultrasound-guided extracorporeal shock wave therapy for plantar fasciitis: a randomized controlled trial. JAMA 2002;288:1364-72.

28. Haake M, Buch M, Schoellner C, Goebel F, Vogel M, Mueller I, et al. Extracorporeal shock wave therapy for plantar fasciitis: randomised controlled multicentre trial. BMJ 2003;327:75. 
29. Klonschinski T, Ament SJ, Schlereth T, Rompe JD, Birklein F. Application of local anesthesia inhibits effects of low-energy extracorporeal shock wave treatment (ESWT) on nociceptors. Pain Med 2011;12:1532-7.

30. Rompe JD, Furia J, Weil L, Maffulli N. Shock wave therapy for chronic plantar fasciopathy. Br Med Bull 2007;81-82:183-208.

31. Lee SJ, Kang JH, Kim JY, Kim JH, Yoon SR,
Jung KI. Dose-related effect of extracorporeal shock wave therapy for plantar fasciitis. Ann Rehabil Med 2013;37:379-88.

32. Park JW, Yoon K, Chun KS, Lee JY, Park HJ, Lee SY, et al. Long-term outcome of low-energy extracorporeal shock wave therapy for plantar fasciitis: comparative analysis according to ultrasonographic findings. Ann Rehabil Med 2014;38:534-40. 